Original Research

\title{
Developing Family Resilience Models: Indicators and Dimensions in the Families of Pulmonary TB Patients in Surabaya
}

\author{
Dhian Satya Rachmawati ${ }^{1}$, Nursalam Nursalam ${ }^{2}$, Muhammad Amin ${ }^{3}$ and Rachmat \\ Hargono $^{1}$ \\ ${ }^{1}$ Faculty of Public Health, Universitas Airlangga, East Java, Indonesia \\ 2 Faculty of Nursing, Universitas Airlangga, East Java, Indonesia \\ ${ }^{3}$ Faculty of Medicine, Universitas Airlangga, East Java, Indonesia
}

\begin{abstract}
Introduction: Family resilience is the process of adaptation and coping in the family as a functional unit. A lack of family involvement in the care programs for TB sufferers is one of the factors of concern. The purpose of this study was to analyze the indicators of the family resilience of patients with pulmonary TB.
\end{abstract}

Methods: This study used an observational analytical method with a crosssectional approach. The study population was the families of new pulmonary TB sufferers in the Surabaya area, taken using the rule of the thumb guideline with a sample of 130 respondents. The sampling technique using was systematic random sampling. The variables in this study were the stages of family resilience: survival, adaptation, acceptance, growing stronger and helping others, which were measured using a questionnaire. The data was analyzed using second CFA.

Results: The results showed that the family resilience model is also the fit model. This refers to the results of the goodness of fit test. Family Resilience $=0.724$ Survival, Family Resilience $=0.762$ Adaptation, Family Resilience $=0.945$ Acceptance, Family Resilience $=0.783$ Growing Stronger and Family Resilience $=$ 0.879 Helping Others.

Conclusion: The results of this study provide information on the stages of family resilience and the ability of each stage so then it can be used as a reference when developing family nursing care plans for patients with pulmonary TB.

\section{ARTICLE HISTORY}

Received: December 09, 2019 Accepted: January 06, 2020

\section{KEYWORDS}

family resilience; tuberculosis; CFA; adaptation; acceptance

\section{CONTACT}

Dhian Satya Rachmawati $\triangle$ dhian.satya.rachmawati2017@fkm.unair.ac.id $\equiv$ Faculty of Public Health, Universitas Airlangga East Java, Indonesia

Cite this as: $\quad$ Rachmawati, D. S., Nursalam, N., Amin, M., \& Hargono, R. (2019). Developing Family Resilience Models: Indicators and Dimensions in the Families of Pulmonary TB Patients in Surabaya. Jurnal Ners, 14(2), 165-171. doi:http://dx.doi.org/10.20473/in.v14i2.16549

\section{INTRODUCTION}

The family has a very important role in maintaining optimal levels of patient health in the face of illness (Samal, 2016). The family support received by the pulmonary TB patients plays an important role in improving treatment adherence. Lack of family and social support predicts poor treatment adherence (Py et al., 2013). Good support and care from the family becomes a consideration when paying special attention to the daily routine of patients with pulmonary TB, especially in terms of medication adherence (Kaulagekar-nagarkar, Dhake, \& Jha, 2012). The family as a system can cause problems and at the same time, be effective in overcoming problems (Friedman, 2010). Family resilience is the process of adaptation and coping in the family as a functional unit. Resilience involves dynamic processes that help them adapt to significant problems. It is this strength and the available resources that enable individuals and families to successfully face crises and problems. It is important to learn the stages of family resilience related to the pulmonary TB sufferers as well as the strength or ability in each stage of family resilience itself. In the previous studies that have discussed the stages of family resilience, they did not test the indicators of each stage

Tuberculosis (TB) is the leading cause of death in the world. An estimated 10.4 million people became ill with TB in 2016 of which $90 \%$ were adults, $65 \%$ were men, $10 \%$ were people living with HIV $74 \%$ in Africa) and $56 \%$ were in the following five countries: 
India, Indonesia, China, the Philippines and Pakistan (WHO, 2017). The detection rate of TB cases, also known as the Case Detection Rate (CDR), in Indonesia in 2020 is estimated to be $>70 \%$ while the success rate of TB treatment, or the Success Rate, is estimated to be (SR) $>85 \%$, even though Indonesia is still included in the ten countries that contribute to TB cases in the world. The number of TB sufferers in Indonesia ranks third in the world after India and China (WHO, 2017).

Surabaya is the second largest city in Indonesia. In 2015 , the number of new cases of pulmonary TB disease in Surabaya was 2,330 patients, the cure rate of BTA+ was $70.43 \%$, and the success rate of the treatment provided was 79.21\% (Dinkes, 2015). Data from the Surabaya City Health Office in 2016 showed that the total number of TB patients in the Surabaya city area was 5,389 patients, with 3,421 patients were reported by 63 Public Health Centers and 1,968 patients reported by 33 public and private hospitals in the Surabaya City area (SITT data source online version 10.04).

Family resilience is expected to be able to increase the independence of the family when caring for family members suffering from pulmonary TB with the end result expected that the patients will have a support system in the form of their family during the treatment process. Family resilience through the 5 stages or processes indicates that when the family is faced with various problems that simultaneously occur in the family, the family will go through 5 phases of resilience. The first stage of the family resilience process is survival (survival). The second stage is where the family begins to adapt to the problems that occur, the third stage is where the family begins to accept the problems and family condition and the next stage is where the family will become stronger because they have experience handling problems. The fifth stage is where the families are able to help others who face the same problems (Lietz \& Strength, 2016).

Every family going through the stages of family resilience does not always follow a sequential process. When the family has stepped into the next phase, it is possible to be thrown back to the initial phase when a new crisis occurs. In addition, in this phase, not every family will be in the same phase to begin with. The accuracy of knowing the current phase of the family and the strength of the family itself helps the family to adapt and to develop in relation to their needs (Lietz \& Strength, 2016). Family resilience shows that the family is able to be independent when caring for the family member suffering from pulmonary TB with the expected result that the patient will have a support system in their family which complies with the care process. The purpose of this study was to analyze the development of a family resilience model in the family of pulmonary TB patients.

\section{MATERIALS AND METHODS}

Table 1. Variables and Sub Variables

\begin{tabular}{|c|c|c|}
\hline Variable & & Sub-Variable \\
\hline \multirow[t]{11}{*}{ Survival (B) } & B .1 & Respect the family \\
\hline & B .2 & Worship \\
\hline & B. 3 & Resolve the problem yourself \\
\hline & B. 4 & Dependent \\
\hline & B .5 & Consulting each other \\
\hline & B .6 & Strong when facing problems \\
\hline & B.7 & Strong faith \\
\hline & B .8 & Mutually keep feeling \\
\hline & B .9 & $\begin{array}{l}\text { Family will help when there is } \\
\text { a problem }\end{array}$ \\
\hline & B .10 & $\begin{array}{l}\text { Be aware that the family } \\
\text { presence is important }\end{array}$ \\
\hline & B. 11 & $\begin{array}{l}\text { Seeking advice from religious } \\
\text { experts }\end{array}$ \\
\hline \multirow[t]{7}{*}{$\begin{array}{l}\text { Adaptation } \\
\text { (A) }\end{array}$} & A.1 & $\begin{array}{l}\text { Families can overcome things } \\
\text { that are not desirable }\end{array}$ \\
\hline & A. 2 & $\begin{array}{l}\text { Open minded to new ways in } \\
\text { the family }\end{array}$ \\
\hline & A. 3 & $\begin{array}{l}\text { Understanding among the } \\
\text { family members }\end{array}$ \\
\hline & A. 4 & $\begin{array}{l}\text { Asking for clarification if there } \\
\text { are things not understood }\end{array}$ \\
\hline & A. 5 & Sharing responsibility \\
\hline & A.6 & Awakened family confidence \\
\hline & A.7 & $\begin{array}{l}\text { Trying new ways to solve } \\
\text { problems }\end{array}$ \\
\hline \multirow[t]{12}{*}{$\begin{array}{l}\text { Acceptance } \\
\text { (P) }\end{array}$} & P.1 & $\begin{array}{l}\text { Accept TB disease-related } \\
\text { difficulties as a part of life }\end{array}$ \\
\hline & P.2 & $\begin{array}{l}\text { Belief that they can overcome } \\
\text { the problem and this becomes } \\
\text { a family commitment }\end{array}$ \\
\hline & P. 3 & Honest to the family \\
\hline & P. 4 & $\begin{array}{l}\text { Compromise if there is a } \\
\text { problem }\end{array}$ \\
\hline & P. 5 & $\begin{array}{l}\text { Communicating in a relaxed } \\
\text { and warm, even humorous, } \\
\text { way }\end{array}$ \\
\hline & P.6 & $\begin{array}{l}\text { Can ask the purpose of the } \\
\text { message that is conveyed by } \\
\text { the family related to the } \\
\text { success of the treatment }\end{array}$ \\
\hline & P.7 & $\begin{array}{l}\text { Solve the problem by } \\
\text { discussion }\end{array}$ \\
\hline & P.8 & $\begin{array}{l}\text { Discussing the problem until } \\
\text { there is a solution that can be } \\
\text { completed and there is } \\
\text { successful treatment }\end{array}$ \\
\hline & P.9 & $\begin{array}{l}\text { Open to expressing their } \\
\text { opinion to get insights }\end{array}$ \\
\hline & P.10 & $\begin{array}{l}\text { Have the power to solve the } \\
\text { problem }\end{array}$ \\
\hline & P.11 & Hearing honest information \\
\hline & P.12 & $\begin{array}{l}\text { Understand the intentions of } \\
\text { the other family members }\end{array}$ \\
\hline \multirow{3}{*}{$\begin{array}{l}\text { Growing } \\
\text { Stronger } \\
(G)\end{array}$} & G. 1 & $\begin{array}{l}\text { Becoming part of a complete } \\
\text { family }\end{array}$ \\
\hline & $\mathrm{G} .2$ & $\begin{array}{l}\text { Making important decisions } \\
\text { related to the treatment of } \\
\text { disease, especially in the family }\end{array}$ \\
\hline & G. 3 & $\begin{array}{l}\text { Able to cope with pain and to } \\
\text { mutually understand the } \\
\text { effects of the disease }\end{array}$ \\
\hline
\end{tabular}




\begin{tabular}{lll}
\hline G.4 & $\begin{array}{l}\text { Able to adapt to the } \\
\text { demands that befall them } \\
\text { as a family in the presence } \\
\text { of disease } \\
\text { Able to solve problems } \\
\text { due to the disease } \\
\text { correctly } \\
\text { Able to resolve the issue } \\
\text { positively }\end{array}$ \\
Helping & G .5 Helping each other with \\
the neighbors who have \\
pulmonary TB
\end{tabular}

Table 2. Demographics of the Respondents $(\mathrm{n}=130)$

\begin{tabular}{lcc}
\multicolumn{1}{c}{ Indicator } & n & \% \\
\hline Family type & 88 & 67.7 \\
$\quad$ Nuclear & 27 & 20.7 \\
Extended & 15 & 11.6 \\
$\quad$ Other Type & & \\
Socioeconomic family & 3 & 2.3 \\
$\quad$ High & 30 & 23.1 \\
$\quad$ Medium & 97 & 74.6 \\
$\quad$ Low & & \\
Position in the family & 20 & 15.4 \\
$\quad$ Husband & 47 & 36.2 \\
$\quad$ Wife & 31 & 23.8 \\
$\quad$ Children & 32 & 24.6 \\
$\quad$ Other & \\
Supervisor the taking of medicine (PMO) & \\
$\quad$ Family & 93 & 71.5 \\
$\quad$ Other & 37 & 28.5 \\
\hline
\end{tabular}

Analytical observational research with a crosssectional approach was used in this study. The population in this study was the families of pulmonary TB patients who had just been diagnosed in the data collection period in the working area of the Public Health Center in the city of Surabaya. Samples were taken through systematic random sampling and calculated using the rule of the thumb with a total sample of 130 respondents. The research instrument used was a questionnaire. The variables in this study are the following dimensions of the family resilience: Survival (B), Adaptation (A), Acceptance (P), Growing Stronger $(\mathrm{G})$ and Helping Others $(\mathrm{H})$ as well as the Dependent Variable (Y) of family resilience. The indicators of each dimension (sub-variable) are as follows:

The data was analyzed using Second Confirmatory Factor Analysis (2CFA). This study has received the recommendation to carry out the research from the National Unity, Politics and Community Protection Agency of Surabaya City. It obtained ethical approval from the Health Research Ethics Commission of the Faculty of Nursing, Airlangga University

\section{RESULTS}

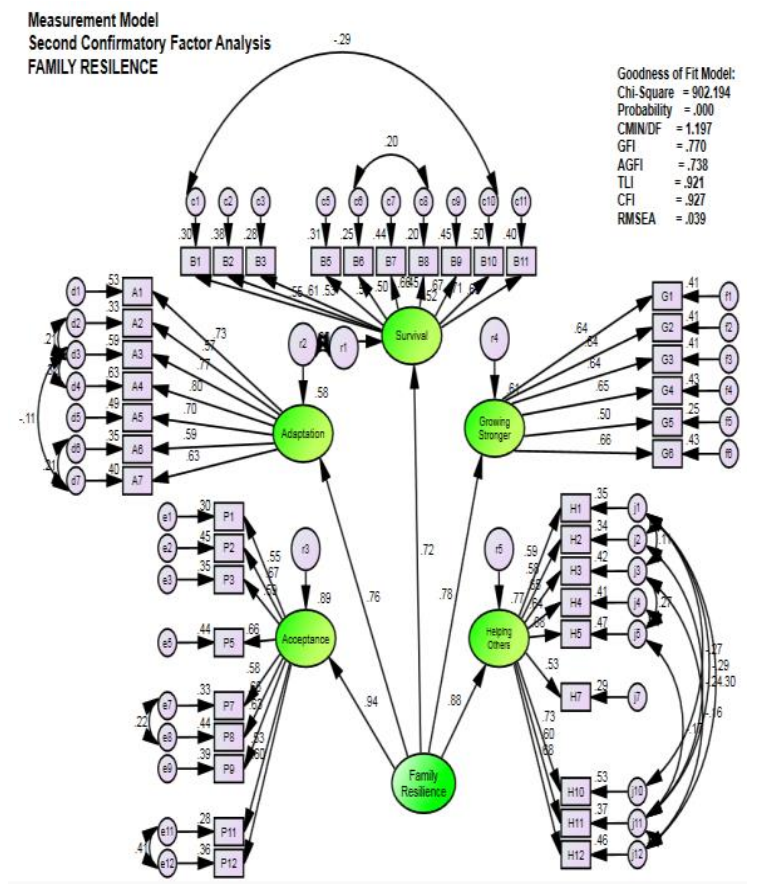

Figure 1. Family Resilience Measurement Model

Table 3. Results of Testing the Family Resilience Model

\begin{tabular}{lccc}
\hline \multicolumn{1}{c}{ Criteria } & $\begin{array}{c}\text { Cut-off } \\
\text { value }\end{array}$ & $\begin{array}{c}\text { Calculati } \\
\text { on } \\
\text { results }\end{array}$ & Information \\
\hline & Expecte & & $\chi^{2}$ with df $=$ \\
Chi-Square & $\begin{array}{c}\text { d to be } \\
\text { small }\end{array}$ & 796.978 & is 818,991 \\
& & & Well \\
Significance & $\geq 0.05$ & 0.135 & Well \\
Probability & $\leq 0.08$ & 0.039 & Well \\
RMSEA & $\geq 0.90$ & 0907 & Well \\
GFI & $\geq 0.90$ & 0838 & Pretty good \\
AGFI & $\leq 2.00$ & 1,057 & Well \\
CMIN / DF & $\geq 0.90$ & 0.921 & Well \\
TLI & $\geq 0.90$ & 0.927 & Well \\
CFI & & & \\
\hline
\end{tabular}


The results of the study focused on 130 families of pulmonary TB sufferers showed the follow results. Table 2 shows that the most family type is that of a nuclear family $(67.7 \%)$. Most families of the pulmonary TB patients have a low socioeconomic level $(74.6 \%)$. The position of the family members who were the respondents was mostly that of a wife (36.6\%). The majority were the supervisors of the patients with pulmonary TB when taking their medicine (71.5\%)

The indicator description includes the minimum, maximum, average and standard deviation value of each indicator as presented in Table 3. CFA modeling requires multivariate normally distributed data. The results of the analysis show that the CR multivariate value of 0.07 lies between the -1.96 values up to 1.96 , thus showing the multivariate normal distribution of the data (Table 4). Next, the 2CFA modeling is presented in the following figure.

The results of testing the measurement model with the complete AMOS program can be seen in the following table.

Table 3 shows that the 7 (seven) criteria used to assess the feasibility of the model were good. It can be said that the measurement model for 2CFA is acceptable, which means that there is a match between the model and the data.

From the appropriate model, each path coefficient can be interpreted. The path coefficients are the hypotheses in this study which can be presented in the following structural equation:

Family Resilience $=0.724$ Survival

Family Resilience $=0.762$ Adaptation

Family Resilience $=0.945$ Acceptance

Family Resilience $=0.783$ Growing Stronger

Family Resilience $=0887$ Helping Others

\section{DISCUSSION}

The families who were respondents in this study were the families of pulmonary TB patients recently diagnosed with pulmonary TB. The analysis shows that most of the families were in the 'acceptance' and 'helping others' phases. This proves that not all families undergo the series of family endurance stages sequentially. Previous studies discussed the stages of the resilience of the families but they did not test the indicators of each stage. The indicators in the family resilience stages will be explained in the following discussion.

\section{Survival}

When a family faces a crisis, loss or trauma, they will usually experience a period of time in which the family members only try to do the minimum of what is needed throughout the day. In this phase, the family has not been able to make adjustments and accept reality. The family is only trying to survive. The survival phase is the phase where the family is only able to get through the problem as it comes every day. Many families explained that before making adaptations to their family life, they just have to find a way to survive. The main family strength in this phase is spiritual power and social support (Lietz \& Strength, 2016).

The results show that the respondents stated the spiritual and religious strength of the family was their most important ability in terms of overcoming and finding meaning in their struggle. During this phase, many families stated that prayer and worship were an important part of survival in the beginning of the crisis. The loading factor of each indicator shows that there are behaviors among the family members who care for each other's feelings, who feel strong when facing problems and who feel the presence of their family. This is a translation of family support and the indicator of asking for help from religious leaders had a greater value than the other indicators. Following this, $67,7 \%$ of respondents with a nuclear family type had a positive impact on family support. When an individual in a family experiences illness, all of the family members are affected because they are connected. The effect on each family member varies in terms of intensity and quality.

During the survival phase, emotional support is very important. Social support in this phase is more about getting help from outside of the family system, including from the extended family, friends, support groups and professionals. In this stage, the family feels an increase in the burden on the family, especially if the sick individual is the husband or wife. The results showed that 47 respondents (36.2\%) were husbands. The husband, as the head of the family, has the main role of providing a decent life for their family so when the husband is sick, it will have an impact on the family. Thus when a family member is sick, the rest of the family feel this as a burden. This is in line with the results of previous studies that showed that the burden of care felt by the family is related to confusion about the illness, emotions, physical, time, and financial and social burdens. This leads to a decrease in the quality of life of family and family functionality. There are opportunities for negative outcomes in relation to family resilience (Fitryasari, Yusuf, Dian, \& Endang, 2018). In this stage, the family needs support from outside of the family, especially from the environment and health workers, to help the family to identify the burden of care and to improve their coping as a part of recovering from adversity.

The problem for the families of TB sufferers is the misunderstanding of the family and community which leads to discrimination related to the disease (Kaulagekar-nagarkar \& Aarti, 2012). Discrimination felt at the beginning of the diagnosis is one of the causes of depression in TB patients and their families (Li-Yun Lee, Heng-Hsin Tung, Shu-Ching Chen, 2017). Social support from the community will be meaningless if there is still stigma and discrimination felt by the TB patients and their families. Fear of contracting $\mathrm{TB}$ is often the reason for this discrimination. In subsequent studies, this will be further investigated in terms of the effect of stigma on family resilience. In this study, the indicator which states that families are interdependent when others 
keep away for fear of contracting the disease has no significance. This shows that at this stage, the family is still oriented towards the impact of any problems internally. This is where the family is more focused on surviving with the problems that they face, which are related to one family member suffering from pulmonary TB. The results of the analysis of the survival stage provide a 0.72 effect on family resilience in the families of pulmonary TB patients.

\section{Adaptation Phase}

This phase refers to the time that the families need to readjust their lives in order to accommodate the crisis that they face. At this time, the family may not really accept new challenges and they begin to find that they need to immediately start making changes. The adaptation phase is the time when changes are made, even before the family really accepts the nature of their current situation. The most relevant family strengths during this period were initiative, flexibility/creativity, and limitation management. Initiative refers to the willingness of the families to take responsibility and to handle situations while the management of restrictions refers to the ability of the families to separate themselves from unhealthy influences (Lietz \& Strength, 2016)

Family creativity is the ability to find several solutions to a problem. Flexibility is the desire of families to try new things when dealing with problems or crises in the family. The results showed that all of the indicators can significantly measure the adaptability of families of the pulmonary TB patients. At this stage, the biggest loading factor value is the family clarifying a problem that is not understood $(0,80)$. Other indicators that have a large enough value include starting to understand each other (0.77), starting to try new things (0.63) and solving problems (0.73). At this stage, the family in this study - by as much as $36.2 \%$ - shows that the representation of the wife is in accordance with the culture in the Surabaya Region. This is how most of the Javanese tribes will act after obtaining approval from the husband as the head of the family who is given authority by the family as decision maker. The analysis shows that the adaptation stage ranks fourth with the structural equation stating that adaptation has an effect of 0.76 on family resilience in the families of patients with pulmonary TB.

\section{Acceptance}

The family strengths in this stage include commitment, insight, communication, and humor. Family commitment refers to the dedication and strong desire of the family as a whole. The family is the first priority. When the family faces difficulties, the strength of the family commitment will make it easier for the family to keep trying to get out of trouble. The provision of interventions that facilitate social support from the family's internal system will foster close relationships and commitment among the family members, especially families at risk. Insight refers to the ability of the families to gain an understanding of the problems that they face.
When the families discuss accepting their situation, they identify communication as a family strength that helps them to achieve acceptance. Affective communication includes expressions of love and attention. Attention and is very important to foster a sense of family cohesiveness. A sense of humor is a family strength that refers to the family's ability to be light in the face of adversity. Humor is discussed as something that helps them to accept their difficulties. Similar to communication, this is also a sign that the reception phase is in progress. Families can make their situation light. This activity reduces their pain while also showing that they are starting to accept what they are facing.

The results showed that indicators P4, P6, and P10 were not significant in terms of measuring the acceptance of the family resilience stage. The indicators show that the family can be compromised if there is a problem, that they can ask for the purpose of the message delivered by the family related to the success of care, and that the family has the power to solve the problem. The four indicators above show that at this stage, the family does not have power. The indicators showing commitment, openness to discussion and communication have a great value. When the families discuss in order to accept their situation, they identify communication as a family power that helps them to achieve acceptance while also showing that acceptance does occur (Walsh, 2017). The results of the analysis show that the acceptance stage ranks first with the structural equation stating that it has an effect of 0.94 on family resilience in the families of pulmonary TB patients.

\section{Growing Stronger}

Growing stronger is when the families acknowledge and experience reinforcement related to the changes they have made so far. The most important family strength during this stage is assessment. When the families experience loss and difficulties but also find meaning in them, they seem to be better able to avoid the negative consequences that are usually associated with high risk situations. This stage is seen when the families move from their initial anger and fear to acceptance, and finally to a place where they can assess the situation positively. The results showed that all indicators that were built can significantly measure the phase of family growth. All of the competencies that show the strength of the family when taking on a positive decision to solve a problem, to accept pain and the impact of pain, and to beginning to feel that they have the ability to resolve the issue properly as a family unit intact. Each indicator above has a value of a loading factor that is almost the same. According to McCubbin (1996) cited by (Chapin, 2015), positive movements are referred to by McCubbin as "bonadaptation", namely behavior that shows changes that move towards growth and maturation. Growing the family resilience ability is not an easy effort. The family should be able to identify any risk factors and manage them in order to achieve a dynamic family situation. In the stage of 
resilience, there is the ability of families to cope with stressors from outside the family, known as risk factors. They respond using the family strength, family resources, and the ability to solve problems within the family, which are collectively referred to as protective factors (Taylor \& Distelberg, 2016).The results of the analysis showed that the stage of growing stronger ranks third with the structural equation stating an effect of 0.78 on the family resilience of the families of patients with pulmonary TB.

\section{Helping Others}

When families can assess their difficulties in a positive way, the family reaches a point where they want to help others. Some suggest that altruistic prosocial behavior helps families to find meaning in adversity (Lietz, 2018). In other words, the families describe their participation in some pro-social behaviors as an effort to help others while also helping themselves. Families have a major contribution towards the pulmonary TB patients. When the nuclear family and extended family provide mutual support, the family resources of education, employment and socioeconomic level also influence this support in accordance with the previous research which states there is a significant relationship between the family factors of family type, level of education, employment, income, healthy home and stressors in the family with the quality of life of pulmonary TB patients (Rachmawati, 2018).

Providing social support is a family strength associated with this phase. The process of resilience grows from the survival stage where families are desperate to receive social support where they help others in turn to give back. The results show that indicators H6, H8, and H9 - which state that the family feels free to be a family member in the social environment, that they provide assistance and gifts for neighbors in need, that they show love and concern for their family members - are not significant in terms of measuring the stage of helping others. This is because the three indicators are still focused on the abilities of the family internally. More precisely, when the family needs support while in this stage, it is more to provide support to others who have similar problems to those experienced by the family. The indicators that show the ability of the families to help others who have similar problems while continuing to show internal efforts to strengthen the family resources, in addition to a sense of security and comfort in the family and environment, plus the social relationships. These are all indicators with high loading values. The results of the analysis show that the stage of growing stronger ranks second with the structural equation stating an effect of 0.88 for the family resilience of the families of pulmonary TB patients.

\section{CONCLUSION}

Based on the results of this study, it can be concluded that the family resilience model is a fit model. This refers to the results of the goodness of fit test. The indicators of each phase of family resilience, which is the development of indicators in the family resilience model as the observed variables in the model, are valid based on the results of the validity test conducted on the measurement model. The construct as described by the observed variable is reliable. The construct of family resilience can be measured clearly using its dimensions or phases which are, sequentially from the greatest value, as follows: acceptance, helping others and growing stronger. Following these three, the adaptation and survival phases have a relatively similar value. The results also showed that not all of the families passed the family resilience stage.

\section{REFERENCES}

Chapin, M. G. (2015). Deployment and Families : Hero Stories and Horror Stories Smith College Studies in Social Work, (July 2009). https://doi.org/10.1080/00377310903130316

Dinkes. (2015). Profil Kesehatan Tahun 2015. Surabaya.

Fitryasari, R., Yusuf, A., Dian, R., \& Endang, H. (2018). International Journal of Nursing Sciences Family members â€TM perspective of family Resilience $\hat{a} €^{\mathrm{TM}} \mathrm{s}$ risk factors in taking care of schizophrenia patients. International Journal of Nursing Sciences, $5(3)$, 255-261. https://doi.org/10.1016/j.ijnss.2018.06.002

Friedman, M. (2010). Buku Ajar Keperawatan Keluarga; Risert, Teori, dan Praktik. (E. Tiar, Ed.) (Edisi 5). Jakarta: EGC.

Kaulagekar-nagarkar, Aarti, D. D. and P. J. (2012). Perspective of Tuberculosis Patients on Family Support and Care in Rural Maharasthra. Indian Journal of Tuberculosis, 59(655), 224-230.

Kaulagekar-nagarkar, A., Dhake, D., \& Jha, P. (2012). Perspective Of Tuberculosis Patients On Family Support And Care In Rural Maharashtra, 411007, 224-230.

Li-Yun Lee, Heng-Hsin Tung, Shu-Ching Chen, C. F. (2017). Perceived stigma and depression in initially diagnosed pulmonary tuberculosis patients. Journal of Clinical Nursing, 26(23-24), 4813-4821. https://doi.org/10.1111/jocn.13837

Lietz, C. A. (2018). Theoretical adherence to family centered practice : Are strengths-based principles illustrated in families â€TM descriptions of child welfare services?, (February). https://doi.org/10.1016/j.childyouth.2010.12.01 2

Lietz, C. A., \& Strength, M. (2016). Stories of Successful Reunification: A Narrative Study of Family Resilience in Child Welfare, (June). https://doi.org/10.1606/1044-3894.4102

Py, K., Sv, A., Rm, M., Js, B., Banerjee, A., \& Ad, K. (2013). Non - Adherence of New Pulmonary Tuberculosis Patients to Anti - Tuberculosis Treatment, (March). https://doi.org/10.4103/2141-9248.109507 
Rachmawati, hian satya; nursalam nursalam; wibowo arief; budiarti astrida; A. R. (2018). Family factors associated with quality of life in pulmonary tuberculosis patients in Surabaya, Indonesia. Indian Journal of Public Health Research \& Development, 9(11), 1772-1776. Retrieved from http://www.indianjournals.com/ijor.aspx?target =ijor:ijphrd\&volume=9\&issue=11\&article=292

Samal, J. (2016). Role of families in tuberculosis care : A case study, (July), 5-8. https://doi.org/10.4103/0975-9727.185020

Taylor, S. D., \& Distelberg, B. (2016). Predicting
Behavioral Health Outcomes Among Low-Income Families: Testing a Socioecological Model of Family Resilience Determinants. Journal of Child and Family Studies, 25(9), 2797-2807. https://doi.org/10.1007/s10826-016-0440-7

Walsh, F. (2017). The Concept of Family Resilience : Crisis and Challenge Special Section Family Resiliance: A Concept and Its Application The Concept of Family Resilience: Crisis and Challenge, (November).

WHO. (2017). Global Tuberculosis Report. Geneva: WHO. 